places in Canada much too high to compete with other available sources of electricity.

Early in 1954 a group, known as the Nuclear Power Branch, was set up in Chalk River to study the design of nuclear reactors for the economic production of power, and a demonstration reactor, known as NPD-2 and proposed by the Branch, is now under construction by the Canadian General Electric Company at Des Joachims on the Ottawa River and is expected to come into operation during 1961. In September 1955, after the decision had been taken to build NPD, the Branch began a study of a full-scale nuclear plant. The results of this study were described in a report in May 1957, but which was given only limited circulation.

However, a booklet* based on the report, giving the background history of the Canadian project and describing in detail the plant designed by the Nuclear Power Branch, has been prepared by J. E. Woolston and has recently been issued. In the first two sections the possible demand for nuclear power in Canada and the general approach to the study including the cost

* Atomic Energy of Canada Ltd. The Canadian Study for a FullScale Nuclear Power Plant. Pp. 64. (Chalk River, Ontario: Atomi Energy of Canada, Ltd., 1958.) 1.50 dollars. target for a competitive nuclear power plant are discussed. The third section deals in detail with the proposed reactor, which has a thermal power of 794 megawatts and a net electrical output of 200 megawatts. Slugs of natural uranium oxide are used as fuel, and it is cooled and moderated by heavy water. The fuel is housed in horizontal pressure tubes through which the pressurized heavy-water coolant passes. There are 200-250 tubes mounted on a square-lattice with a pitch of one foot. A feature of the design is the high burn-up planned for the unenriched oxide, which is considered to be of greater economic advantage than the improvement of the steam conditions and the rather poor thermal efficiency of the plant. The final sections in the report deal with the range of studies carried out by the Branch and the alternative systems investigated; pertinent Chalk River experience; and the estimate of cost of the nuclear plant and its operation. The names of the members of the staff of the Nuclear Power Branch who participated in the studies leading to the proposed reactor are listed in one appendix, and in another complete data on the main components of the reactor are set out.

\title{
RESEARCH IN ALBERTA
}

$\mathrm{T}$ HE thirty-eighth annual report of the Research Council of Alberta* records generally satisfactory progress in all projects during the calendar year 1957 and also in the recruitment of staff of high calibre. A feature of the year was the development of the geological research and survey operations which led to the initiation of survey operations in the north-east corner of Alberta in the Precambrian Shield area. The expansion of the co-operative basic cloud physics research programme with particular reference to the problem of hail in Western Canada was also noteworthy. In the work on coal, evidence was obtained that the calorific value decreases considerably when coals were exposed to the air for prolonged periods, and the thermograms of several coal fractions and of three dated fossil woods were determined. In other differential thermal analysis studies it was observed that sulphur dioxide can modify extensively the course of the pyrolysis of coal. A study of the grindability of coal was completed, and considerable progress made in studies of fluidized coal carbonization.

A theoretical analysis of the flow of stratified water and oil in horizontal pipe-lines agreed well with experimental observations, and progress is reported in the catalytic desulphurization and oxidation with nitric acid of organic sulphur compounds. The study of detailed trace metal and component geochemistry of four major and several minor oilfields was completed; engineering studies continued on the hightemperature pyrolysis of natural gas and a process was developed for removing nitrogen from natural gas. An infiltration study on a river terrace south of Camrose indicated that certain surface water supplies in Alberta can be purified by this technique. Results obtained in studies on electrosomatic flow into clay soils provide a starting point for computing the power

* Research Council of Alberta. Thirty-eighth Annual Report, 1957. (Report No. 77.) Pp. 56. (Edmonton: Queen's Printer, 1958.) requirements necessary to reduce the moisture content of soil by this method, and besides work on the strength, stability and compaction of a base cover material, the instability conditions in bridge abut. ments were investigated and the problem of frost action received continued attention.

The biological cycles programme, which was brought to a virtual close by the death of Dr. W. Rowan, has indicated a rather dramatic increase in grouse and rabbit populations in many areas. Studies on the nutritive value of rape-seed oil indicate that fermenting and drying ground rape-seed prior to oil extraction remove two of the toxic factors and that the high temperatures used in extracting the oil may be partly responsible for the varying feeding value of commercial rape-seod oil meals. The adsorption areas of acetylene, ethylene and ethane on Charcoal No. 2222 have been measured, and it appears that the less 'active', finer-pored charcoal may be more valuable for certain dynamic separations of gases, as in chromatographic column, a technique which is proving of increasing value. A weather radar set has been installed at Penhold and used to follow the detailed courses of precipitating storms within 100 miles, while the hail-reporting network now covers some 15,000 square miles in central Alberta. Lapsetime cloud photography was also expanded and the commercial hail-suppression programme operated over 400 square miles in the southern part of the hail project area. Ground-water conditions were surveyed in five districts and the answering of inquiries is an important part of the ground-water programme. The palæobotanical laboratory continued to be concerned chiefly with describing and cataloguing the Edmonton Paskapoo fossil floras in central Alberta, and microslides have now been made of all the species of modern conifer woods in the type collection. A list of publications is appended. 